\title{
Diablotextron
}

\section{Intersecciones genéricas. Autoetnografía y autobiografía en Trans- generismos (2006) de Norma Mejía}

Intersections of genre. Autoetnography and autobiography in Norma Mejia's Transgenerismos (2006) ${ }^{1}$

\author{
JUAN MARTÍNEZ GIL \\ UNIVERSITAT JAUME I DE CASTELLÓ
}

\begin{abstract}
Resumen: Transgenerismos (2006) de Norma Mejía fue la primera tesis doctoral sobre la transexualidad defendida en España por una persona trans. No obstante, el texto posee un valor añadido, ya que puede leerse en clave autobiográfica debido a sus características textuales. En el presente trabajo indagaremos las posibilidades de esta lectura autobiográfica a partir de los desplazamientos que produce la metodología antropológica a la que se adscribe su autora, la autoetnografía. A continuación, mostraremos los mecanismos que Mejía utiliza para dialogar en su escritura con ambas convenciones, la literaria y la académica.
\end{abstract}

Palabras clave: Estudio trans, autobiografía, autoetnografía, Norma Mejía, Transgenerismos

Abstract: Norma Mejia's Transgenerismos (2006) was the first Phd dissertation about transsexuality defended in Spain by a trans person. Nevertheless, the text has an added value as it can also be read as an autobiography because of its textual characteristics. This paper focuses on the possibilities of that reading, based on the shifts produced by the anthropological methodology to which the author is adscribed: the autoethnography. In addition, we would show the mechanisms used by Mejía in order to dialogue, in her writing, with both discourses: literary and academic

Key words: Trans Studies, Autobiography, Autoetnography, Norma Mejía, Transgenerismos

\footnotetext{
${ }^{1}$ El presente artículo ha sido realizado gracias a la ayuda predoctoral FPU19/00371 financiada por el Ministerio de Universidades del Gobierno de España. Se enmarca en el proyecto "La construcción discursiva del conflicto: territorialidad, imagen de la enfermedad e identidades de género en la literatura y en la comunicación social" (FFI2017- 85227-R).
} 


\section{Introducción}

Las autobiografías de mujeres trans irrumpieron a partir de los años 60 en el panorama narrativo anglosajón y francés ${ }^{2}$, especialmente a partir de la publicación de la biografía de Coccinelle de Mario Costa (Coccinelle est lui, 1963) y su traducción al inglés. Si atendemos a la información recogida en textos como los de Christine Jorgensen o Jan Morris -ambos recopilados por Ames (2005) - observamos desde sus relatos de infancia las mismas pautas conductuales -jugar con muñecas o vestirse con ropa de la madre a escondidas- que los discursos médicos a partir de los años 50 habían comenzado a calificar de "transexualidad".

Estos discursos médicos favorecieron una patologización de la transexualidad y promulgaron la imagen de la "buena transexual" que tenía que odiar sus genitales y excitarse con varones, lo que sumado a los citados precedentes textuales autobiográficos y a la tradición cultural de la confesión, acabarían creando un subgénero de autobiografía trans. Por ello, Ken Plummer (1995:42) afirma que estas narrativas terminaron por imponerse a la propia experiencia vital de las personas a las que pretendían reflejar, de forma que se crearon una serie de itinerarios vitales preestablecidos que toda trans que se considerara como tal debía seguir. Así, tras un periodo de degradación y supervivencia, las protagonistas de estas autobiografías acaban por ensalzar el momento en el que consiguen su meta: modificar sus genitales quirúrgicamente para abandonar las desdichas que provoca su sexo de nacimiento, a modo de bildungsroman trans (Ames 2005: xii).

No obstante, el panorama literario de este tipo de obras en España esbozaría un escenario bien diferente según Mérida Jiménez (2018). La censura y persecución de las minorías sexuales durante la dictadura franquista (19391975), el carácter de las sociedades católicas que limita la confesión al ritual sacramental, el origen socioeconómico y la escasa formación académica de la mayoría de las personas que se atrevían a vivir como trans -aquellas que no tenían nada que perder-, así como las drogas y el sida que diezmaron a la po-

\footnotetext{
2 Utilizamos aquí el término "trans" para referirnos a personas transgénero, transexuales y travestis por resultarnos el más adecuado para identificar a las autoras de una serie de textos anteriores a los años 90, momento en el que se empezó a gestar una conciencia que diferenciaba las tres categorías que incluye el término (Stryker 2008: 145-149).
} 
blación lumpen del país, provocaron unas condiciones de existencia casi nulas y una muy difícil distribución para este tipo de documentos en la segunda mitad del siglo XX. Tan solo a partir del año 2000, la aparición de algunas publicaciones que rescatan relatos biográficos en la España de los 60, 70 y 80, arrojarán un poco de luz al panorama de las historias de vida trans de esta época: volúmenes como las Memorias trans (2006) de Pierrot o De niño a mujer. Biografía de Dolly Van Doll (2007). Así,

\begin{abstract}
auspiciadas por el paso del tiempo, animadas por el reconocimiento de una legislación que ya no las ignora, incluso rehabilitadas por un 'movimiento gay y lésbico' que ya no las evita, la primera década del mileno puede definirse como el del inicio de la recuperación de la memoria trans en España (Mérida Jiménez 2018: 161).
\end{abstract}

Curiosamente, la Serie General Universitaria de Edicions Bellaterra publicó en 2006 Transgenerismos. Una experiencia transexual desde la perspectiva antropológica de Norma Mejía. Este ensayo, derivado de su tesis doctoral en Antropología Social por la Universitat de Barcelona, resulta de especial interés por diversos motivos. En primer lugar porque, aunque se presente como un texto académico, una altísima cantidad de su contenido corresponde al relato experiencial de la propia autora, circunstancia que nos permite leerlo en clave autobiográfica. Este desplazamiento del género académico al relato autobiográfico se produce debido a la particular metodología que emplea: Transgenerismos es una etnografía extrema o autoetnografía, un tipo de trabajo antropológico en el que la visión investigadora (etic) y la del objeto de investigación (emic) se fusionan. ${ }^{3}$ Norma Mejía se retrata como una transexual que estudia la experiencia de la transexualidad.

A través de una cantidad ingente de anécdotas y relatos, pretende teorizar sobre este fenómeno en un plano psicológico, biológico, cultural, social y antropológico utilizando, además del material autobiográfico, entrevistas, diferentes documentos y citas de naturaleza académica. Todo ello se culmina con unos anexos formados por el certificado que acredita su vaginoplastia, el infor-

\footnotetext{
${ }^{3}$ La distinción entre emic y etic es introducida en la Antropología por Kenneth Pike, lingüista estructuralista (Harris 1982: 49-61). De esta forma "lo que caracteriza a las operaciones de tipo emic es la elevación del informante nativo al status de juez último de la adecuación de las descripciones y análisis del observador [...] El rasgo distintivo de las operaciones de tipo etic es la elevación de los observadores al status de jueces últimos de las categorías y conceptos empleados en las descripciones y análisis" (Harris 1982: 47).
} 
me psiquiátrico que le diagnostica un trastorno de identidad sexual y la entrevista, de veintiocho páginas, a una transexual que lleva por título "Lola, una superviviente" (343-370).

Nacida en Bogotá en 1944, a los diecinueve años Norma Mejía se mudó a París y más tarde a Barcelona, donde se estableció. Estudió cinematografía, derecho y un doctorado en Antropología. Trabajó a lo largo de su vida como realizadora, redactora, prostituta y abogada, habiendo ejercido de esto último en el Col-lectiu de Transsexuals de Catalunya (CTC). Su posición como disidente de género en el sistema heteropatriarcal (transgénero/transexual) la convierte en un sujeto imprevisto en el campo de la academia y en el de la producción autobiográfica en España ${ }^{4}$. Su relato de vida va desde su juventud como varón que forma parte de una acomodada burguesía colombiana, hasta sus noches de prostitución en el Arco barcelonés a sus casi cincuenta años.

La hipótesis de la que partimos es la posibilidad de ofrecer una lectura autobiográfica de Transgenerismos, aunque no se adscriba oficialmente a este género ni sea catalogada editorialmente como tal. En el presente trabajo, abordaremos las especificidades que permiten entender el texto en clave autobiográfica, así como sus interrelaciones con la práctica etnográfica. A su vez, analizaremos las distorsiones de la convención que se encuentran en el propio texto a partir del uso de un discurso híbrido que oscila entre lo literario y lo teórico.

\section{Transgenerismos en clave autobiográfica}

Transgenerismos está formado por diecisiete capítulos, unas conclusiones a modo de resumen de su historia de vida, una bibliografía y tres anexos. En él, Mejía repasa diferentes conceptos o experiencias a partir de ejes temáticos que no quedan imbricados en un orden temporal (autobiográfico) o una metodología académica, sino que se suceden de forma aleatoria. De esta forma, pasamos sin ningún tipo de transición de un capítulo como "5. Los inicios" (87-104), donde expone sus primeras experiencias con el mundo trans barcelonés, a otro como "6. Precedentes y realidades trans" (105-122), en el que re-

\footnotetext{
${ }^{4}$ No podemos olvidar que se trata de la primera tesis doctoral en Antropología sobre la transexualidad defendida en el sistema universitario español por una transexual. Del mismo modo que su única novela, Lorena mi amor (2004), es la primera novela escrita por una trans publicada originariamente en España.
} 
sume y reproduce algunos estudios sobre el activismo y la realidad trans estadounidense. Esta peculiar composición genera múltiples interrogantes: ¿qué desplazamientos permiten la lectura autobiográfica del texto? ¿Existe una intención memorística voluntaria por parte de la autora o se trata de un cambio azaroso? ¿Podemos entender Transgenerismos exclusivamente como texto autobiográfico o exclusivamente como texto académico?

La primera respuesta nos la proporciona Mejía en una de las últimas páginas del volumen: Transgenerismos tiene un origen textual desafortunado que puede explicar su cierta amorfía como ensayo resultado de su tesis doctoral. Su autora relata cómo tuvo un problema con el ordenador y se vio obligada a rehacer la tesis con retazos que conservaba en diferentes lugares, gracias a la ayuda inestimable de su amiga Noemí. Esta circunstancia adversa se convierte en la justificación diegética de su modus operandi, lo que provoca una estructura, en ocasiones, inconexa y fragmentaria. Mejía considera este suceso como anecdótico y apenas lo menciona en un paréntesis: "La redacción de esta tesis me absorbe bastante, y mi poca habilidad con el ordenador no me ayuda mucho (hace poco borré accidentalmente toda la tesis y tuve que reconstruirla, no sé si completa, a partir de las partes de las que Noemí había hecho copias electrónicas)" (324).

Una confesión tan grave como el hecho de desconocer si ha podido recomponer de forma "completa" su propia tesis doctoral se introduce sin aparente importancia 5 . De hecho, esta anécdota que podría explicar la peculiar composición del texto, también puede ofrecer una respuesta al contenido autobiográfico en sí. Según la presente confesión, Mejía considrea su tesis doctoral como una carga, un asunto que le absorbe y que le quita "una cosa actualmente muy preciosa para mí: tiempo" (324); por otro, Mejía reconoce que ha tenido que reconstruir todo el texto con notas y fragmentos, pues sus archivos informáticos se han borrado y tiene que presentar un trabajo académico. No resultaría descabellado pensar que, finalmente, Mejía se inclina por convertir su

\footnotetext{
${ }^{5}$ Hacemos referencia al texto como "tesis doctoral" aunque manejemos la edición de Bellaterra publicada como "ensayo". Esto se debe a que la autora utiliza esta nomenclatura en todo momento dentro del texto así como al hecho de que fuentes cercanas al tribunal que la evaluó nos han confirmado que el texto es practicamente idéntico. A pesar de que la tesis se encuentre fuera de consulta en el catálogo de la Universitat de Barcelona y no hayamos podido cotejarla, se dan certezas suficientes como para considerarla dentro del género "tesis doctoral".
} 
propia vida en materia académica, de forma que la ampliación con relatos de experiencias -propias y ajenas-y con documentos dispersos, pueda ser la mejor opción para depositarla y recuperar su "precioso tiempo". El hibridismo textual que descubrimos en su trabajo no es por tanto casual, sino causal.

La escritura de Transgenerismos queda marcada por este suceso. Durante los primeros cuatro capítulos encontramos un texto con un tono muy académico, lleno de referencias, citas y digresiones teóricas. Sin embargo, a partir del quinto, Mejía realiza toda una explosión memorística y cambia el rumbo escritural del trabajo, introduciéndose de lleno en el formato de la historia de vida. Tan solo los capítulos 6,9 y 13 volverán a mantener un tono casi completamente académico -aunque igualmente incluyen materia vital en forma de anécdotas. De esta manera, de los diecisiete capítulos que forman Transgenerismos, siete de ellos $(1,2,3,4,6,9,13)$ se presentan con una metodología escritural más próxima a la convención universitaria y diez $(5,7,8,10,11,12$, $14,15,16,17)$ ofrecen una recreación autobiográfica en forma de narración, si bien encontramos referencias bibliográficas, probablemente incluidas para mantener la apariencia del formato tesis doctoral.

Mejía, pues, lleva a cabo de forma simultánea una narrativa autobiográfica y un relato investigador. Como en una carrera de fondo, es el relato de su vida el que acaba por sobrepasar la dimensión académica. Ella misma llega a afirmar con respecto a la elección de su tema de tesis doctoral que "me ocurrió con mis estudios de antropología lo mismo que con mi vida: había intentado excluir de ellos a la transexualidad, y la transexualidad había acabado apoderándose de ellos" (130). Más allá de la opción que apunta, podemos afirmar que es su propia vivencia la que se adueña de su trabajo, también a nivel metodológico, estructural y genérico. Así, conforme más se aproxima el final de la tesis, observamos con mayor nitidez esta imposición del yo autobiográfico sobre el yo académico. Incluso cuando se introducen referencias teóricas -citas, disquisiciones, uso de datos estadísticos-, las anécdotas personales con las que pretende ilustrar su utilidad son a la vez usadas como argumento de ejemplo y autoridad, en tanto que reflejan su propia experiencia como sujeto trans legitimado para corroborar el tema que trata. 
No obstante, según indica Mérida Jiménez (2015: 80), existe otra variable de suma importancia que permite a Mejía hacer uso de este recurso de supervivencia que es la escritura autobiográfica, que no es otra que el uso de la etnografía extrema aplicada como metodología de trabajo 6 . Por ello, considero indispensable establecer algunas interrelaciones entre la escritura autoetnográfica y la autobiográfica con el objetivo de valorar los debates y sinergias que generan ambas modalidades y sus posibilidades textuales.

\section{Autoetnografía como autobiografía}

Ya en las primeras páginas del volumen, Mejía explica en qué consiste la metodología de su tesis: "Imparcial y parcial, con un punto de vista tan pronto etic como emic, pues a la vez que sujeto, soy uno de los objetos de esta tesis (lógicamente, del que tengo más información)" (Mejía 2006: 21). A continuación, incluye dos citas académicas sobre la etnografía extrema de Bolin y Granskog (2003) y asume ya durante todo el texto que este es su método de trabajo: "desde el principio he querido dejar clara mi condición de transexual, lo que adscribe este estudio a la corriente de la etnografía extrema" (39).

Dentro del ámbito de las ciencias sociales, la autoetnografía consiste en un tipo de práctica cualitativa que basa su trabajo de campo en la unión de la visión emic y etic, la creación de un trabajo etnográfico a partir de la propia experiencia del investigador como sujeto y objeto de estudio. Ellis, Adams y Bochner (2015) afirman que "para hacer y escribir autoetnografía, el investigador aplica los principios de la autobiografía y de la etnografía. Así, como método, la autoetnografía es, a la vez, proceso y producto" (250). Por lo tanto, la deshabilitación de las fronteras entre etic y emic procedentes de la etnografía tradicional permite un espacio propicio al uso del relato personal y autobiográfico. En este contexto, quizás la pregunta más pertinente no sería tanto qué desplazamientos realiza Mejía en el plano etnográfico, sino en qué momento la literatura autobiográfica puede ser entendida como una práctica etnográfica.

\footnotetext{
${ }^{6}$ Mejía utiliza la terminología de "etnografía extrema" que toma de Bolin y Granskog (2003). En la actualidad, y especialmente en el ámbito hispánico, el término con mayor difusión para este tipo de enfoque es el de "autoetnografía" (Esteban 2004, Blanco 2012).
} 
No obstante, la utilización del relato autobiográfico no es de nueva creación en el terreno de las ciencias sociales. La metodología cualitativa conocida como "historias de vida", popularizada por la Escuela de Chicago a partir de los años 20 , consiste en la realización de investigaciones sobre la sociedad en base a las experiencias de sus individuos -usualmente a través de la entrevista como formato (Feixa 2000). De hecho, Jesús M. de Miguel en su manual Auto/biografías (2017:94-95) diferencia entre "historia de vida" y "biografía/autobiografía" aludiendo a que la primera es un testimonio oral y la segunda un testimonio escrito. Nieto Piñeroba (2008: 25) realiza una distinción idéntica pero aludiendo a "narrativas" en lugar de "biografía/autobiografía"7. Por lo tanto, cuando el etnógrafo realiza un ensayo a partir de la narración de su propia historia personal, este resultaría en una investigación autoetnográfica.

La cercanía entre las "historias de vida" de las ciencias sociales y las "autobiografías" literarias queda planteada por de Miguel, de forma que "parecen novelas. No suele quedar claro si se trata de ensayos (no ficción) o de novelas (ficción). Suelen tener un alto grado de contenido literario. Las palabras, usos del lenguaje, expresiones, tienen una importancia central” (2017: 83). Se descubren, así, intersecciones posibles entre la literatura y la sociología cualitativa en la lectura de cualquier documento que por sus características se encuentre en la frontera epistemológica de ambos campos de estudio. Un volumen como el de Mejía, aunque se aproxime en sus primeros capítulos a la convención académica y la investigación teórica, acaba por ceder ante su propia historia de vida a la manera literaria, autobiográfica, lo que genera la disolución de fronteras entre un género textual y el otro, una oscilación que apenas puede ser salvada por sus paratextos ${ }^{8}$.

\footnotetext{
${ }^{7}$ La perspectiva que toma el presente trabajo no realiza esta distinción. En cualquier caso, Transgenerismos contendría ambos formatos, pues recoge hasta tres entrevistas a diferentes mujeres transgénero que se deberían considerar en el primer grupo -a María (97-102), Berta (145-146) y Lola (343-370)- y relatos vivenciales de la propia Mejía, que pertenecerían al segundo.

8 Nótese que hay un cambio de título en la tesis doctoral registrada en 2005 en la UB (Transgenerismos: ensayo de etnografía extrema) y la publicación de Bellaterra de 2006 (Transgenerismos. Una experiencia transexual desde la perspectiva antropológica). Podría tratarse de una decisión editorial para salvaguardar las distancias genéricas dentro de esta "Serie General Universitaria".
} 
De esta forma, los recursos narrativos presentes en Transgenerismos, y que principalmente asumimos como propios de la literatura, también tienen cabida en la práctica autoetnográfica. Al igual que de Miguel, Mercedes Blanco incide en las posibilidades retóricas que descubrimos en dicho formato ensayístico, ya que "una característica imprescindible para la mayoría de los autores revisados situados en la corriente de la autoetnografía es la presencia de una estructura narrativa —que incluye una trama o el argumento del relato" (2012: 172-173).

En la obra de Mejía, numerosos fragmentos con "estructura narrativa" cuentan historias pertenecientes a sus propias memorias y son expuestos como parte integrante del trabajo doctoral. En "17. Viaje al otro sexo en el país de las kathoey" (313-324), relata su vaginoplastia en el Hospital Internacional de Phuket, Tailandia. Sin embargo, no se trata de un episodio aislado en donde pretende dar una muestra sociológica de la experiencia de la cirugía de reasignación sexual (CRS), sino que existe toda una cohesión literaria que produce conexiones con el relato de capítulos anteriores. Así, tras explicar el deseo de operarse en "12. La decisión" (247-256) se remite al inicio del capítulo 17: "Como no hay plazo que no se venza, los largos nueve meses con que empecé a preparar el viaje a Tailandia acabaron convirtiéndose en los pocos segundos que quedaban para que despegara el avión rumbo a Londres, la primera etapa" (313). El tiempo diegético del relato acompaña al tiempo de lectura, donde tras cinco capítulos, "nueve meses" pasaron. No pretendo insinuar que Mejía establezca un relato lineal, puesto que no lo hace, sino más bien demostrar cómo utiliza formatos narrativos y figuras retóricas propios de la literatura que no acostumbran a darse en la escritura académica.

Por este motivo, y según la bibliografía consultada, el trabajo de Mejía quedaría legítimamente insertado en el género de la autoetnografía ${ }^{9}$. Como planteaba Mérida Jiménez (2015) son precisamente las posibilidades de esta modalidad antropológica las que le otorgan la moldeabilidad necesaria para

\footnotetext{
9Según la subclasificación de autoetnografías que proponen Ellis, Adam y Bochner (2015), Transgenerismos podría catalogarse dentro de las "narrativas personales" que "proponen entender al sí mismo o a algún aspecto de la vida, ya que se entrecruza con el contexto cultural, se conecta con otros participantes como co-investigadores, e invita a los lectores a entrar en el mundo del autor y utilizar lo que aprende allí para reflexionar, entender y hacer frente a sus propias vidas" (258).
} 
una lectura en clave literaria. En este punto, podemos responder al tercero de nuestros interrogantes y afirmar que no reside ninguna contradicción en el hecho de que su trabajo sea al mismo tiempo una etnografía y una autobiografía. Resulta evidente que no podemos eliminar ninguna de las dos caras de esta moneda textual, en tanto que la existencia de una literariedad muy manifiesta no contradice la investigación etnográfica en sí, pues esta se produce a través de ella.

A pesar de que Norma Mejía se adapte al planteamiento y a las posibilidades que le brinda la etnografía extrema, cuando pensamos su trabajo como una autobiografía en su sentido clásico ${ }^{10}$, descubrimos que podemos encontrar una serie de fricciones. Bourdieu afirma que la autobiografía se desarrolla "según un orden cronológico que es también un orden lógico, desde un principio, un origen, en el doble sentido de punto de partida, de comienzo, pero también de principio, de razón de ser, de causa primera, hasta su término que es también una meta" (1989: 28). Si partimos de esta convención, Transgenerismos supondría una ruptura por partida doble. Por un lado, el viaje vital que se nos describe no es lineal y heroico, sino inverso y degradado. No se narra un punto inicial de pobreza y penurias hasta llegar a una historia de éxito y prosperidad, sino más bien un recorrido en el que un sujeto de clase medio-alta decide voluntariamente convertirse en lumpen, "no porque ganase mucho dinero prostituyéndome ni porque me fuese imposible encontrar otra forma de ganarme la vida, pero sí de vivir como mujer" (Mejía 2006:17). De hecho, si seguimos los postulados teóricos de Mejía, no habría necesidad de someterse a una CRS tal y como los discursos médicos promulgan, para considerarse como transexual. Sin embargo, nuestra autora concluye el itinerario vital que propone con su vaginoplastia, avalada por un certificado quirúrgico. Se crea así una tensión explícita entre aquello que propone en su trabajo -el transgenerismo-, y su decisión vital -la transexualidad de quirófano.

\footnotetext{
10 "Récit rétrospectif en prose qu'une personne réelle fait de sa propre existence, lorsqu'elle met l'accent sur sa vie individuelle, en particulier sur l'historie de sa personnalité" (Lejeune 1975: 14). [Un relato retrospectivo en prosa que una persona real hace de su propia existencia, cuando pone el acento en su vida individual, especialmente en la historia de su personalidad]. Traducción propia.
} 
Por otro lado, Mejía no escribe una historia "desde el parto-y-el-bautizo hasta la muerte-y-el-funeral" (de Miguel 2017: 71), sino una narración a retazos y desordenada de su vida como mujer transgénero, cuyos antecedentes solo interesan a propósito de su identidad sexual. Por ello, incidirá en momentos puntuales de su historia anterior, como la primera vez que ve a Christine Jorgensen en los medios de comunicación (153, 325), o su estancia de juventud en París donde comienza a hormonarse sin llegar a asumir completamente el género femenino $(89,325)$. Transgenerismos propone un camino discontinuo en tanto que no existe un orden cronológico en su escritura autobiográfica.

De hecho, ante la pregunta inicial de si existe una intención memorística voluntaria por parte de la autora o se trata de un cambio azaroso, me inclino a pensar que esta discontinuidad temporal es uno de los factores que nos obligan no tanto a plantear una cuestión de voluntades, sino de posibilidades. La línea de fuga para su experiencia e identidad que representa la oportunidad de realizar un trabajo como la autoetnografía, es la única certeza que podemos tener. La autobiografía, entonces, no se plantearía intencionalmente como tal, sino que surge de unas posibilidades dadas y una necesidad de expresión latente. Así, mencionará hasta en dos ocasiones su acercamiento a la etnografía extrema como un encuentro tardío pero afortunado $(131,231)^{11}$.

En cualquier caso, Mejía no es tan solo una doctoranda en su cincuentena -defiende su tesis con 61 años- sino que se trata de una persona con una formación cultural muy sólida debido a su clase social de origen. Forzosamente ha tenido que leer autobiografías en francés y en inglés -en Transgenerismos cita la de Jan Morris (160), la de Christine Jorgensen (175) y la de Coccinelle (174-175), entre otras. Este bagaje se relaciona a la perfección con el hecho de que previamente ha sido escritora de una novela "no sé si impulsada por el deseo de expresarme o por el de ganar dinero" (300). Si tenemos en cuenta su licenciatura en Derecho y sus más que amplias posibilidades de tener ingresos

\footnotetext{
${ }^{11}$ Me inclino a no considerar su obra como parte del género "autoficción", pues Transgenerismos carece de la intención autorial que en dicho género resulta fundamental y que presenta a un personaje identificado como autor y a unos hechos como presuntamente ficticios. Mejía relata sus experiencias sin esta mediación, con un valor de verdad mucho más próximo a los postulados tradicionales de la autobiografía y al pacto autobiográfico de Philipe Lejeune (1975). No obstante, ello no implicaría ningún valor esencialista en torno a la verdad autobiográfica, ya que como indica Pozuelo Yvancos (2006), el pacto de lectura no deja de ser una construcción cuyo principal partícipe es el lector.
} 
por otras vías - de las cuales elige la prostitución- podemos intuir que "el deseo de expresarme" supone una opción mucho más creíble, sin ser excluyente. Nos encontramos, por tanto, ante una persona con una cultura muy amplia que además ha practicado la literatura y que finalmente se decanta por escribir una autoetnografía.

¿Cómo no va a usar retórica literaria si la antropología le permite utilizarla, ya la ha practicado anteriormente, se encuentra a gusto en este ámbito, y precisamente lo que desea es acabar su tesis cuanto antes para ganar su "preciado tiempo"12? A la luz de estas circunstancias, podemos entender un volumen como Transgenerismos como literario o casi literario. En este punto, el final de la obra ("18. Conclusiones" 325-329) resulta determinante para comprender que, en realidad, la dimensión biográfica es aquella con la que identifica su trabajo, lo que nos brinda una clara "clave de lectura" (Mérida Jiménez 2015: 85). En esta última parte, Mejía realiza aquello que no ha hecho en los diecisiete capítulos previos: resumir cronológicamente su vida como transexual desde que ve a Christine Jorgensen por primera vez hasta que decide operarse y se plantea su futuro.

De la literatura a la etnografía y de la etnografía a la literatura, la lectura que aquí propongo queda amparada por ambas disciplinas en cuanto posibilidad teórica, y por la obra en cuestión en cuanto realidad textual. Un efecto boomerang tal no puede sino entenderse bajo unas circunstancias vitales muy concretas que quedan perfectamente explicadas en el relato autobiográfico. Sin embargo, conviene detenerse en observar cómo dialoga la autora con las convenciones entre las que se mueve, y qué fisuras se producen en la convención de los géneros textuales que transita.

\section{(De)generación textual en Transgenerismos}

Dos rasgos principales caracterizan, a mi parecer, la escritura de esta identidad discursiva que oscila entre géneros de forma muy particular: el collage textual y la presencia de un discurso transdisciplinario. El primero de ellos,

\footnotetext{
12 Mari Luz Esteban (2004) apunta muy certeramente el término de "emergencia de la autoetnografía" (16) para definir a los sujetos que encuentran en el género una legitimación de su condición de supervivientes desde el relato de su propia experiencia vital.
} 
también el que más llama la atención en una lectura superficial, consiste en la inclusión de documentos de una extensión muy considerable para ilustrar algunas de sus posiciones teóricas. No obstante, estos no parecen ejemplificar un discurso académico trazado en torno a ejes temáticos bien hilvanados, sino que más bien es su inclusión la que vertebra los capítulos en los que quedan insertos. Así, puede provocar la sensación de que todo el capítulo "2. Vacilantes comienzos. El «Stonewall» del 78" (41-52) gira en torno a la reproducción del editorial de la revista La Pluma de 1978 (47-50) y en el capítulo "3. Situación en el Tercer Mundo. Una violencia despiadada" (53-72) el Informe de Amnistía Internacional (66-68) y grandes cantidades de fragmentos pertenecientes a la novela autobiográfica trans brasileña Princesa (68-72), acaparan hasta seis páginas. ${ }^{13}$

Precisamente la aparición de estos fragmentos, muy presentes tanto por su extensión como por su abundancia, provocan un efecto de collage textual que dota de cierta identidad al texto y a su forma de escritura y provoca extrañamiento. Sin embargo, y con relación a la tragedia informática con la que la autora escuda esta posible amorfía genérica, quizás resultaría más acertado pensar esta acumulación textual a modo de metáfora discursiva de su propia identidad. A base de incluir los documentos con los que se siente más identificada de entre aquellos que encuentra en el transcurso de su investigación, Mejía forma un macrotexto que la representa o que representa sus ideas sobre qué implica ser transgénero.

La segunda de las características que muestra una fricción en los formatos usualmente adscritos a la escritura universitaria y a la literaria, se refleja en el discurso que podríamos calificar de transdisciplinario ${ }^{14}$, pues se mezclan ambos formatos y aleja a cualquier lector que acceda a su texto exclusivamente como ensayo doctoral o exclusivamente como ejemplo de literatura autobiográfica. Esta hibridez discursiva se encuentra en diversas manifestaciones que podemos subdividir en dos grandes grupos: fragmentos sin cita académica ex-

\footnotetext{
${ }^{13}$ A lo largo de la tesis, Mejía hace uso de este recurso en diversas ocasiones (112-120, 97 $102,145-146,272-274,291-298)$, probablemente debido a la necesidad de acabar el trabajo doctoral.

${ }^{14}$ La elección del sufijo "trans-" en lugar de "inter-" no es baladí. "Trans-" en tanto cruza de una disciplina a otra sin ningún tipo de transición o atenuante, "trans" en tanto su contenido es siempre beligerante e identitario.
} 
plícita, pero que contienen un alto grado de formalidad, junto a reflexiones autobiográficas y fragmentos en los que se intercalan citas académicas literales que acompañan a estas.

En el primer subgrupo, descubrimos pasajes en los que Mejía es capaz de incluir en su discurso teórico apuntes vitales. Por ejemplo, interpelando a "personajes" del relato autobiográfico presentes durante todo el volumen:

\begin{abstract}
Las explicaciones de Fausto-Sterling me parecen muy ricas en contenido. Si el niño explora más y permanece más tiempo lejos de sus padres y la niña usa prendas de vestir que limitan sus movimientos, él hace más ejercicio. Y el desarrollo físico normalmente es directamente proporcional al ejercicio físico que se hace cuando el cuerpo aún se está formando. El hijo de la Rubia perteneció a la penúltima quinta que hizo el servicio militar, y durante él creció cinco centímetros, cuando parecía que ya no crecería más. (277)
\end{abstract}

Tras 277 páginas de anécdotas y relatos, el lector sabe sin necesidad de aclaración quién es la Rubia y conoce su inestable pero duradero romance lésbico con la protagonista (Mejía). Un comentario de esta índole tan solo es posible en un contexto en el que la Rubia se ha constituido como "personaje" de una materia autobiográfica, especialmente después del relato sobre sus noches de prostitución en el Arco, donde se narran sus primeros encuentros, colaboraciones laborales e incluso su matrimonio (189-193): "El día de nuestra boda fue uno de los más felices de nuestra vida, para ambas. No hicimos nada especial. Una ceremonia sencilla, con una juez muy maja, comida, las dos solas, en un buen restaurante y, por la tarde, cine" (191).

En otros capítulos, Mejía no rescata su materia vital para tratar apuntes teóricos, sino que a partir de su propia experiencia comienza a divagar y a introducir reflexiones académicas. Así, se relatan sus viajes a Nueva York en busca de trans, donde

encontré muchas, todas ellas, absolutamente todas, latinas, de origen humilde y dedicadas a la prostitución. Buena parte de ellas eran colombianas. ¿Coincidencia, o es que esa era la composición de la población trans de ese momento? No lo sé, pero más recientemente Bailey hizo en Chicago un estudio sobre [...]" (285).

Dentro del segundo subgrupo de discurso transdisciplinario, Mejía se sirve de citas literales, ya sea porque las comenta disruptivamente con materia vital, o porque en medio de una narración autobiográfica decide ilustrar la vi- 
vencia en cuestión con ellas ${ }^{15}$. De esta forma, podemos observar pasajes donde se hace un uso de las memorias como comentario o ratificación de fragmentos teóricos, por ejemplo, reflexionando sobre las posibilidades lúdicas del ménage à trois:

\begin{abstract}
Estoy completamente de acuerdo con el escritor colombiano Fernando Vallejo cuando afirma: «... el sexo entre tres es más divertido. Introduce la variación en la partitura. Es puro Mozart (El País, 20 de octubre de 2004, p. 48)».

Sin embargo, Noemí sostiene que como mejor se hace el amor es entre cinco. No lo sé, nunca lo he probado. (202)
\end{abstract}

Al igual que sucede en el caso de la Rubia, el lector no necesita explicación sobre quién es Noemí, pues ya a la altura de la página 202 ha sido introducida como una de sus mejores amigas y su experiencia le sirve para revalidar las palabras de Vallejo. En este sentido, resulta muy interesante comprobar cómo la mayoría de los comentarios de este tipo sirven para justificar la cita en cuestión, a modo de argumento ejemplo, que a su vez es argumento de autoridad: ¿quién mejor para corroborar los postulados teóricos sobre la transexualidad que sus amigas transexuales y ella misma? ${ }^{16}$

En el caso inverso, también abundan los fragmentos en los que se hace uso de citas con formato académico para comentar experiencias personales, de forma quizás más convencional en el formato doctoral, pero totalmente inusual en el discurso autobiográfico clásico, incluso en los casos de autoetnografía. Así, respecto a la existencia de transexuales de mujer a hombre descubrimiento que parece fascinar a Mejía como demuestra la nota inicial del trabajo (14)- decide justificar sus propias impresiones, esta vez con citas teóricas directamente en inglés que a continuación siempre traduce:

\footnotetext{
Manuel, sonriente y relajado, contaba, entre otras cosas, el tiempo y el dinero que le había costado obtener su documentación de hombre (dos años y dos millones de pesetas). Otros se mostraban reservados, y hablaban y se dejaban ver poco. En conjunto, los chicos parecen haber descubierto que: «Exposure — publicity- is a two-edgeds word: it both serves and harms. It can educate, and it can misinform.
}

\footnotetext{
${ }^{15}$ No he descubierto nada parecido en los relatos autoetnográficos que he leído, en los que cuando adoptan su versión autobiográfica abandonan totalmente la convención académica (Blanco 2012), o cuando son plenamente académicos relatan la materia vital como contenido científico (Langarita 2015). En definitiva, ordenan el discurso para que no se produzca esta hibridación, quizás dominados, en uno y otro caso, por la estética literaria y académica.

${ }^{16}$ Estos apuntes personales a las citas académicas incluidas en texto se repiten en diversas ocasiones $(82,166,260,281-282,300)$.
} 
It can lead to better opportunities, and it can cause some avenues of possibility to recede, recoil, dry up» (Green, Jamison, 1998, p. 154) [...]. (148)

El personaje de Manuel parece corroborar las lecturas de Mejía en materia de transexualidad masculina y exposición pública, por lo que decide ilustrar con ellas su descripción, revistiéndola con un halo de autoridad. ${ }^{17}$

El dilatado conjunto de discursos transdisciplinarios mostrado no tiene pretensión de ser exhaustivo sino ilustrativo de una forma de escritura muy propia, me atrevería a afirmar que insólita. La mezcla de elementos y discursos reina en Transgenerismos del mismo modo que se generan incoherencias textuales que producen una sensación de desorden constante ${ }^{18}$. Todas estas modalidades textuales teóricas y autobiográficas nos llevan a la construcción de un yo que se escapa de los moldes habituales de los géneros que transita.

\section{Conclusiones}

Una adversidad crea un género textual que se corresponde con la hibridez propia de Norma Mejía como mujer transgénero, quien jamás tuvo una vida del modo que reflejan otros textos autobiográficos trans: Norma jamás quiso ser femenina, jamás sintió atracción sexual por hombres, jamás quiso operarse -aunque lo acabe haciendo- e incluso fluctúa entre el género femenino y el masculino en determinadas ocasiones. Ella misma, al igual que su texto, se presenta como transgenérica. Su propia ambigüedad identitaria se va a corresponder con el carácter textual que impregna su obra, tomando así distancia de las maneras convencionales de narrar unas memorias (trans) y de las de escribir una tesis doctoral, creando un texto absolutamente original en el contexto hispánico ${ }^{19}$.

\footnotetext{
17 Igualmente, son múltiples los fragmentos en los que podremos observar este recurso aplicado a diferentes situaciones $(180,200,235,318)$.

${ }^{18}$ Mérida Jiménez (2015: 83) muestra fragmentos donde Mejía comenta que ya está operada y fragmentos donde afirma que es una mujer transgénero -que como explica teóricamente, son las que no se han sometido a la CRS-. De esta forma, se evidencian diferentes momentos escriturales de la tesis que no han sido bien curados en su edición final para mantener una coherencia y quedan al descubierto bajo una lectura atenta.

${ }^{19} \mathrm{La}$ existencia de algunos volúmenes que también juegan con la convención autobiográfica dentro del espacio académico pondría en jaque dicha afirmación, como Testo Yonki (2008) de Preciado. En cualquier caso, considero que el trabajo de Preciado no presenta las mismas características que el de Mejía, ya que Testo Yonki es un ensayo perfectamente trazado, donde teoría y vida confluyen con éxito estético e intelectual, sin las disrupciones, collages e hibridaciones de Transgenerismos -y por tanto, sin su particular autenticidad.
} 
Como certeramente apunta Mari Luz Esteban (2004: 18) "los/as autores/as que se autoetnografían no aceptan los límites impuestos dentro de la profesión, los márgenes de la tarea investigadora ni del conocimiento, que sólo a primera vista parecen infinitos". Ante la necesidad de inclusión del yo en el formato académico por un lado, y de la teorización sobre ese mismo yo en el formato autobiográfico por otro, las reglas prototípicas de ambos géneros textuales quedarían deconstruidas. Mejía crea, aunque accidentalmente, un texto transformal y transteórico sobre la vida de una trans muy poco transexual aunque innegablemente transexual -dos certificados médicos, de cirugía y de psiquiatría, lo corroboran. Un formato de identidad que inunda su escritura en un plano temático y formal, ofrece un tejido de experiencias personales y colectivas y en última estancia y causa primera, la lleva a escribir. ¿Podría existir una forma de escritura más visceralmente identitaria?

\section{Bibliografía}

Ames, Jonathan (ed.) (2005). Sexual Metamorphosis: An Anthology of Transsexual Memoirs. New York: Vintage

BLANCO, Mercedes (2012). “¿Autobiografía o autoetnografía?”. Desacatos, n.ำ 38, pp. 169-178.

Bolin, Anne y Jane Granskog (2003). Athletic Intruders: Ethnographic Research on Women, Culture, and Exercise. Albany: State University of New York Press.

BOURDIEU, Pierre (1989). "La ilusión biográfica”. Historia y Fuente Oral, n.ำ2, pp. 27-33.

Costa, Mario (1963). Coccinelle est lui. Paris: Les Presses du Mail.

De Miguel, Jesús (2017). Auto/biografías. Madrid: Centro de Investigaciones Sociológicas.

ElLIS, Carolyn; Tony E. AdAMS y Arthur P. BochneR (2015). "Autoetnografía: un panorama”. Astrolabio. Nueva época, n. 14, pp. 249-278.

ESTEBAN, Mari Luz (2004). "Antropología encarnada. Antropología desde una misma". Papeles del CEIC, n. 12, pp. 1-22. En: http://www.ehu.es/CEIC/papeles/12.pdf [Fecha de acceso: 15 julio 2019].

FARIAS DE AlbuQUERQUe, Fernanda y Maurizio JANNELLI [1994] (1996). Princesa. Traductor Joaquín Jordá. Barcelona: Anagrama.

FEIXA, Carles (2000). "La imaginación autobiográfica". Nómadas, n. 18, pp.8093.

HARRIS, Marvin (1982). El materialismo cultural. Traductor Gonzalo Gil Catalina. Madrid: Alianza.

LANGARITA, Jose Antonio (2015). En tu árbol o en el mío. Una aproximación etnográfica a la práctica del sexo anónimo entre hombres. Barcelona: Bellaterra.

LEJEUNE, Philippe (1975). Le pacte autobiographique. Paris: Seuil. 
Matos, Pilar (2007). De niño a mujer. Biografía de Dolly Van Doll. Córdoba: Arco Press.

MEJía, Norma (2006). Transgenerismos. Una experiencia transexual desde la perspectiva antropológica. Barcelona: Bellaterra.

MEJÍA, Norma (2004). Lorena mi amor. Barcelona: La Tempestad.

MÉRIDA JIMÉNEZ, Rafael M. (2018). "Hacia una cartografía de las textualidades autobiográficas trans en España”. En Dieter Ingenschay (ed.), Eventos del deseo. Sexualidades minoritarias en las culturas/literaturas de España y Latinoamérica a finales del siglo XX. Madrid-Frankfurt: Iberoamericana-Vervuert, pp.155-168.

MÉRIDA JIMÉNEZ, Rafael M. (2015). "Norma Mejía: narrativas y memorias transgenéricas". En Jorge Luis Peralta y Rafael M. Mérida Jiménez (eds.), Memorias, identidades y experiencias trans. (In)visibilidades entre Argentina y España. Buenos Aires: Biblos, pp. 78-94.

Nieto Piñeroba, José Antonio (2008). "Entrante". EnTransexualidad, intersexualidad y dualidad de género. Barcelona: Bellaterra, pp. 11-32.

PieRrot (2005). Memorias trans. Transexuales, travestis, transformistas. Barcelona: Morales i Torres.

Plummer, Ken (1995). Telling Sexual Stories. Power, Change and Social Worlds. Londres: Routledge.

Pozuelo Yvancos, José María (2006). De la autobiografía. Teoría y estilos. Madrid: Crítica.

PreCiado, Beatriz (2008). Testo yonki. Madrid: Espasa-Calpe.

STRYKER, Susan (2008). "Transgender history, Homonormativity and Disciplinarity”. Radical History Review (January), n.ำ 1, pp. 145-157.

Fecha de recepción: 26 de septiembre de 2021

Fecha de aceptación: 26 de noviembre de 2021 